\title{
Sistem Informasi Penjualan Minuman Coklat di Mr. D Berbasis Website
}

\author{
Kemal Farouq Mauladi \\ Program Studi Teknik Informatika, Fakultas Teknik, Universitas Islam Lamongan \\ Jl.Veteran No.53A Lamongan, Jawa Timur 62213. \\ Kemalfarouq@unisla.ac.id
}

\begin{abstract}
Abstrak
Perkembangan Teknologi Informasi berjalan dengan amat pesat, tidak dapat dipungkiri disemua sektor termasuk dunia usaha memanfaatkan kemajuan teknologi untuk mempermudah pekerjaannya. Dengan kecanggihan teknologi, semua keterbatasan sarana, jarak dan waktu menjadi permasalahan yang sangat mudah. Dalam dunia usaha, baik perusahaan maupun sektor lainnya dituntut untuk melakukan inovasi dalam menarik pembeli. Sektor usaha makin dipicu untuk menggunakan teknologi yang maju sebagai alat atau media untuk bertahan dan memenangkan persaingan yang semakin hari semakin ketat. Dengan adanya persaingan usaha di bidang yang sejenis, maka untuk dapat mengimbanginya salah satu cara adalah perusahaan harus mengikuti perkembangan teknologi seperti memanfaatkan internet untuk membuat situs yang dapat melayani pemesanan secara online. Saat ini proses transaksi penjualan minuman di Mr. D masih dilakukan secara manual yaitu setiap transaksi dicatat kedalam buku transaksi begitupula untuk nota pembelian masih dilakukan secara manual, maka dalam menciptakan kegiatan transaksi yang cepat dan efisien dibutuhkan system informasi penjualan dengan media internet dengan pemanfaatan website. Sistem yang dibangun dalam penelitian ini menggunakan dreamweaver dan database mysql yang diharapkan bisa mempermudah dalam transaksi penjualan di toko Mr.D.
\end{abstract}

Kata kunci: Transaksi penjualan, Website, Mysql.

\section{PETUNJUK UMUM}

Perkembangan Teknologi Informasi berjalan dengan amat pesat. Tidak dapat dipungkiri disemua sektor termasuk dunia usaha memanfaatkan kemajuan teknologi untuk mempermudah pekerjaannya. Dengan kecanggihan teknologi, semua keterbatasan sarana, jarak dan waktu menjadi permasalahan yang sangat mudah. Dalam dunia usaha, baik perusahaan maupun sektor lainnya dituntut untuk melakukan inovasi dalam menarik pembeli. Karena pasalnya, dalam hal pemasaran, pihak penjual selalu mengalami kendala seperti terbatasnya jangkauan wilayah pemasaran dan marketting produk cukup kesulitan menemukan pembeli yang tepat. Sektor usaha makin dipicu untuk menggunakan teknologi yang maju sebagai alat atau media untuk bertahan dan memenangkan persaingan yang semakin hari semakin ketat. Dengan adanya persaingan usaha di bidang yang sejenis, maka untuk dapat mengimbanginya salah satu cara adalah perusahaan harus mengikuti perkembangan teknologi seperti memanfaatkan internet untuk membuat situs yang dapat melayani pemesanan secara online.
Dalam penelitian ini, penulis melibatkan sebuah usaha Es Coklat "Mr.D" yang telah berdiri selama 5 tahun. Usaha ini memiliki banyak pelanggan. Namun usaha ini belum masuk ke bisnis melalui media online yang informatif untuk pemesanan yang menjelaskan secara detail minuman yang di tawarkan sebagai media promosi sehingga memudahkan pemesanan oleh pelanggan terhadap minuman yang ada di Rumah Makan ini. Selain itu transaksi yang dilakukan masih dengan cara harus pergi ke Outlet Es Coklat "Mr.D" tersebut, dan proses transaksi tersebut tidak terarsip dengan baik sehingga pemilik usaha merasa kesulitan untuk mengetahui jumlah pemasukan setiap bulannya. Proses manual ini juga membutuhkan waktu yang lebih untuk mengitung hasil pendapatan.

Berdasarkan uraian diatas, dibutuhkan sistem informasi yang memudahkan sistem manajemen di Es Coklat "Mr.D" tersebut. Maka dari itu penyusun tertarik untuk membuat aplikasi berbasis web untuk pemesanan minuman Es Coklat tersebut dengan "Sistem Informasi Pemesanan Minuman Coklat Berbasis Web di Mr.D Lamongan". 


\section{TINJAUAN PUSTAKA}

Penelitian menurut (Handita dkk, 2012) yang berjudul Sistem Informasi Penjualan berbasis Web Pada Usantex, penelitian ini menghasilkan aplikasi toko online dengan menggunakan bahasa pemrograman PHP, MySQL sebagai database, Macromedia Dreamweaver 8 sebagai editor HTML dan Corel Draw sebagai image editor. Aplikasi ini memiliki tiga fungsi utama. Pertama yaitu untuk user umum, setiap pengunjung website bisa melihat katalog produk, menggunakan layanan website, tetapi tidak bisa melakukan pemesanan produk. Kedua adalah anggota yang bisa melakukan pemesanan produk. Terakhir yaitu administrator yang bisa melakukan pengelolaan data produk, mengelola pesanan dan memperoleh laporan.

Penelitian yang berikutnya menurut (Yessy dan Suprianto, 2017) yang berjudul Sistem Informasi Penjualan Produk Krupuk Berbasis Web Responsive (Studi Kasus pada UD Summber Makmur), hasil dari peneltian ini sistem informasi penjualan yang efektif yaitu yang dikelola penuh oleh seorang administrator dalam mengendalikan semua informasi yang berkaitan dengan tata kelola data produk dan data penjualannya, serta diberikan fasilitas menu khusus bagi customer untuk memperoleh informasi dan dapat melakukan transaksi.

Penelitian yang selanjutnya menurut (Qomaruddin dkk, 2018) yang berjudul Sistem Informasi Penjualan Batik Berbasis Web pada Toko 10S Pasar Grosir Setono, hasil dari penelitian ini adalah Sistem Informasi Penjualan online meliputi pemakaian situs oleh pelanggan seperti registrasi pelanggan, pembelian dan pemesanan barang, pemberitahuan informasi terbaru. Pengaturan situs oleh admin baik poses pengamanan berbagai data, pengiriman barang, penambahan barang dan transaksi jual beli. Semua hal tersebut digunakan untuk menampung data-data untuk mempermudah proses sistem informasi.

Peneltian yang selanjutnya menurut (Hayat dan Riyandho, 2019) yang berjudul Rancang Bangun Sistem Informasi Penjualan Berbasis Web Pada Pt Samator Gas Industri. Hasil penelitian ini terdapat menu fasilitas Pembayaran, customer dapat melakukan pembayaran sendiri kemudian menunjukkan bukti pembayaran tersebut melalui pengunggahan (uploading) bukti pembayaran atau transfer ke dalam sistem, pembuatan surat jalan, Faktur dan kwitansi tidak lagi secara manual hanya perlu menginput berdasarkan nomor surat dan semua data-datanya telah terintegrasi pada database, Pengelolaan Aplikasi dan Administrasi Penjualan, Administrator Sales dapat memantau order yang masuk dari semua customer, dan memproses selanjutnya, pembuatan laporan, laporan penjualan dapat langsung dibuat secara online dan dapat langsung dicetak sesuai dengan periode (setiap bulan) yang diinginkan. Aplikasi dalam penelitian ini menggunakan PHP dan database Mysql.

Berdasarkan penelitian terdahulu aplikasi yang digunakan dengan versi PHP macromedia dreamveawer serta belum responsive dan masih banyak beberapa tools yang belum ada seperti backup database sedangkan pada penelitian yang dilakukan menggunakan aplikasi dengan versi CodeIgniter dan bisa responsive, serta beberapa penambahan bebearapa fasilitas seperti menu user bisa melakukan pemesanan dan pembatalan apabila tidak sesuai dengan pilihan, pada menu transaksi dan pembayaran dilakukan dari aplikasi atau bisa menggunakan transfer melalui bank jadi user ketika datang ke outlet bisa langsung menggambil pesanan tanpa harus mengantri terlebih dahulu, pada menu pengiriman pemesanan apabila user masih di Wilayah Kabupaten Lamongan maka diberikan pengriman gratis kepada user dengan catatan pembelian di minimal 3 item pesanan, sedangkan menu backup database diberikan menu export dan import yang di gunakan untuk menyimpan data produk, data user, data transaski.

\subsection{Konsep Dasar Sistem}

Menurut Moekijat (2011:152), "Sistem adalah setiap sesuatu terdiri dari obyek-obyek, atau unsur-unsur, atau komponen-komponen yang bertata kaitan dan bertata hubungan satu sama lain, sedemikian rupa sehingga unsurunsur tersebut merupakan satu kesatuan pemrosesan atau pengolahan yang tertentu".

Sistem menurut (Andi Kristanto, 2007) adalah suatu jaringan kerja dari prosedurprosedur yang saling berhubungan, berkumpul bersama-sama untuk melakukan suatu kegiatan atau untuk menyelesaikan suatu sasaran yang tertentu. Suatu sistem yang baik harus mempunyai tujuan dan sasaran yang tepat karena hal ini akan sangat menentukan dalam mendefiniskan. 


\subsection{Unified Modeling Language}

UML (Unified Modeling Language) adalah bahasa standar yang digunakan untuk menjelaskan dan memvisualisaikan artifak dari proses analisis dan disain berorientasi objek. UML menyediakan standar pada notasi dan diagram yang bisa digunakan untuk memodelkan suatu system. UML dikembangkan oleh 3 orang "berorientasi objek", yaitu Grady Booch, Jim Rumbaugh, dan Ivar Jacobson. UML menjadi bahasa yang bisa digunakan untuk berkomunikasi dalam perspektif objek antara user dengan developer, antara developer dengan developer, antara developer analis dengan developer desain, dan antara developer desain dengan developer pemrograman.

Unified Modeling Language merupakan kumpulan bahasa yang berguna untuk melakukan sebuah abstraksi sistem yang berbasis objek. Selain itu, UML juga bisa digunakan untuk mempermudah dalam pengembangan aplikasi secara berkelanjutan.

UML dimulai secara resmi pada Oktober 1994, ketika Rumbaugh menggabungkan kekuatan dengan Booch. Mereka berdua lalu bekerja bersama di Relational Software Cooperation. Proyek ini memfokuskan pada penyatuan metode booch dan Rumbaugh (OMT). Pada bulan Oktober 1995, UML merilis versi 0.8 dan pada waktu yang sama juga Jacobson bergabung dengan Relational. Cakupan dari UML pun semakin meluas. Kemudian dibangunlah persatuan untuk UML dengan beberapa organisasi yang akan menyumbangkan sumber dayanya untuk bekerja, mengembangkan,dan melengkapi UML.

\subsection{Prototyping}

$\begin{array}{cccr}\text { Prototype } & \text { di definisikan } & \text { sebagai } \\ \text { pendekatan ke } & \text { desain } & \text { sistem } & \text { yang } \\ \text { mengembangkan } & \text { model } & \text { kerja } & \text { yang }\end{array}$ disederhanakan dari sistem. Prototype, atau rancangan awal ini, dapat dengan cepat dan murah untuk dibangun dan diberikan pada para pemakai atau diuji. Berikut merupakan gambar alur proses yang terjadi di Prototype. Prototypeprototype dibuat untuk memuaskan kebutuhan klien dan untuk memahami kebutuhan klien lebih baik.

\section{METODE PENELITAAN}

Menurut (Sugiyono, 2018) metode penelitian pada dasarnya merupakan cara ilmiah untuk mendapatkan data dengan tujuan dan kegunaan tertentu. Cara ilmiah berarti kegiatan penelitian yang didasarkan pada ciri-ciri keilmuan, yaitu rasional, empiris, dan sistematis.

\subsection{Metode Pengumpulan Data}

Penelitian ini menggunakan dua jenis data yaitu data primer dan data sekunder. Data primer adalah data yang dikumpulkan secara langsung oleh peneliti (Sugiyono, 2018). Data primer yang digunakan berupa hasil observasi dan wawancara. Data sekunder adalah data yang diperoleh secara tidak langsung oleh peneliti melalui orang lain atau dokumen (Sugiyono, 2018). Data sekunder yang digunakan berupa bahan pustaka atau literatur, penelitian terdahulu, dan dokumen pendukung dari Es Coklat Mr.D

Teknik pengumpulan data pada penelitian ini adalah wawancara, observasi dan dokumentasi. Observasi dilakukan secara langsung di Es Coklat Mr.D yang beralamat di Jalan Raya Mastrip, Kecamatan Lamongan, Kabupaten Lamongan, Jawa Timur. Observasi dilakukan dengan mengamati proses transaksi pembelian dan pemesanan produk minuman coklat serta dokumen-dokumen yang terkait. Wawancara dilakukan dengan mengadakan tanya jawab kepada pemilik toko Mr.D agar mendapatkan data dan dokumen yang terkait dengan pemesanan, pengiriman, dan transaksi pembayaran yang ada di toko tersebut.

\subsection{Metode Pengembangan Perangkat Lunak}

Metode pengembangan perangkat lunak yang di lakukan dalam penelitian ini yaitu metode prototyping dimana memungkinkan client melakukan evaluasi sistem yang dirancang di awal oleh developer dan mencoba sebelum diimplementasikan. Metode perangkat lunak yang dilakukan dimulai dari pembuatan desain sistem, Aplikasi yang digunakan yaitu PHP dengan versi CodeIgniter Web Framework, yang responsif serta data base mysql.

\subsection{Implementasi}

Implementasi sistem adalah sebuah prosedur yang dilakukan untuk menyelesaikan desain sistem yang ada dalam dokumen desain sistem yang telah disetujui dan diuji,menginstall dan memulai menggunakan sistem baru 
atau sistem yang diperbaiki untuk mengganti sistem yang lama. Sistem yang telah dirancang selanjutnya akan diteruskan tahap pengimplementasian sistem. Jadi tahap implementasi sistem ini merupakan kelanjutan dari tahap perancangan sistem. Pada tahap implementasi sistem ini difokuskan pada penerapan sistem yang telah didesain kepada bahasa pemrograman yang sesuai, sehingga pada akhirnya diperoleh hasil yang sesuai dengan yang diinginkan. (Roxana Bassi, 2010)

\section{HASIL DAN PEMBAHASAN}

Hasil dari penelitian ini adalah Aplikasi pemesanan minuman coklat Mr.D dengan memanfaatkan CodeIgniter dengan data base mysql.

\subsection{Perancangan Proses}

Perancangan proses atau permodelan sistem menggunakan Unified Language Model (UML) terdiri dari Use Case, dan Sequence Diagram. Perancangan use case melibatkan 2 aktor yaitu Admin selaku pemilik, dan User selaku pembeli dengan masing-masing hak akses yang dapat dilihat pada gambar 1 Use Case Diagram Proses Sistem Informasi Penjualan.

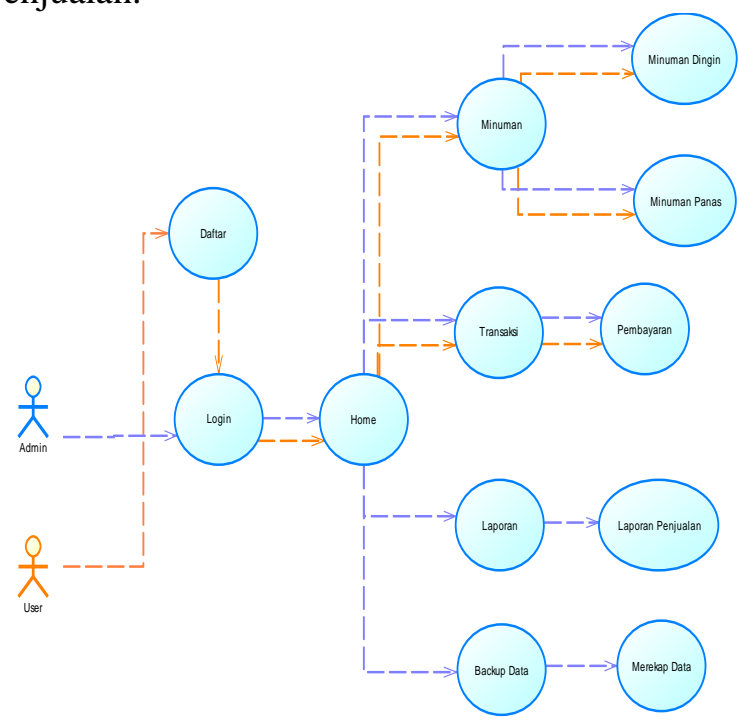

Gambar 1. Use Case Diagram

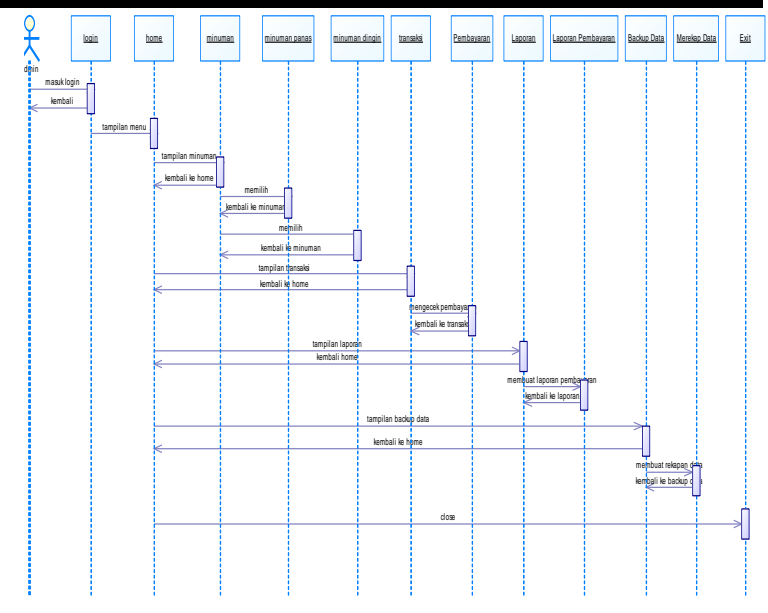

Gambar 2. Sequence Diagram

\subsection{Perancangan Database}

Perancangan basis data meliputi tabeltabel yang dirancang untuk mengelola aplikasi Sistem Informasi penjualan coklat pada Mr.D. Tabel yang dirancang terdiri dari 7 tabel yaitu : Tabel Admin, Tabel Minuman, Tabel Ongkir, Tabel Pelanggan, Tabel Pembayaran, Tabel Pembelian, Tabel Pesan. Relasi antar tabel pada sistem informasi penjualan coklat pada Mr.D adalah one to one, one to many, gambar 4 merupakan database relasional pada penelitian ini.

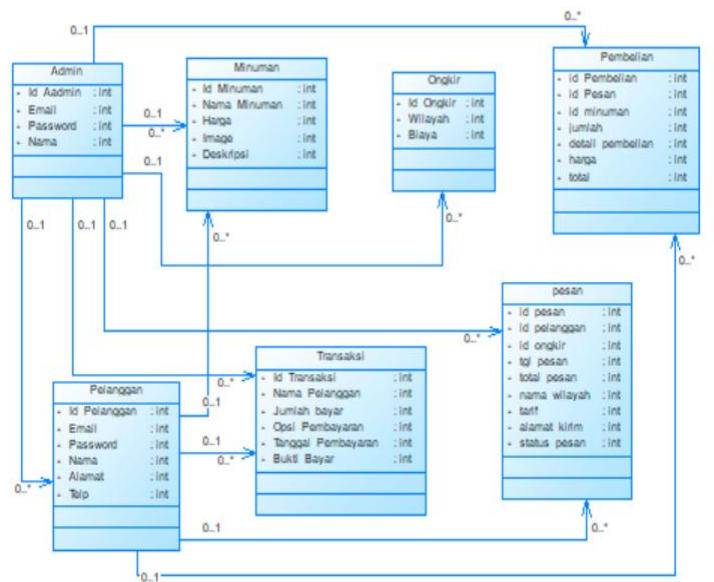

Gambar 4. Relasi Antar Tabel

\subsection{Perancangan Antar Muka dan Pembuatan Aplikasi}

Perancangan antarmuka terdiri dari antarmuka untuk Administrator dimana user level admin di berikan akses kepada pemilik, usaha. Untuk antar muka aplikasi bisa dilihat pada gambar 5 . 


\section{Login Admin}

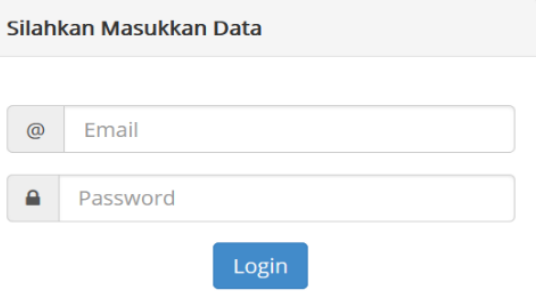

\section{Gambar 5. Menu Administrator}

Setelah login sistem berhasil maka, antar muka selanjutnya adalah halaman utama menu administrator. Halaman utama antar muka administrator dapat dilhat pada gambar 6 .

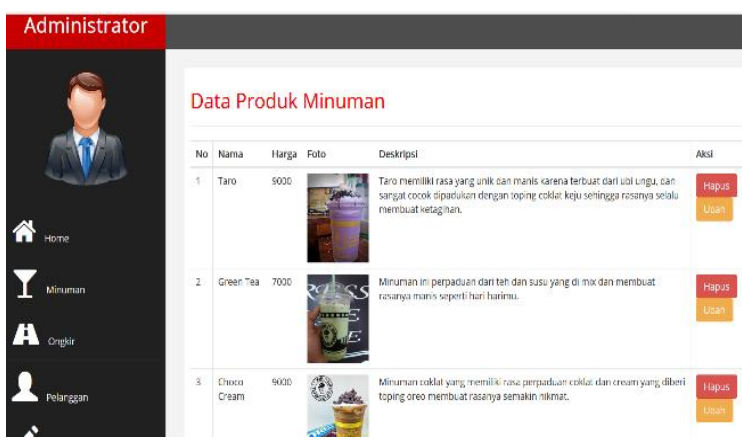

Gambar 6. Menu Utama Admin

Dari menu utama pada antar muka admnistrator maka, selanjutnya adalah antar muka untuk input data produk minuman. Pada menu antar muka produk bisa dilihat pada gambar 7.

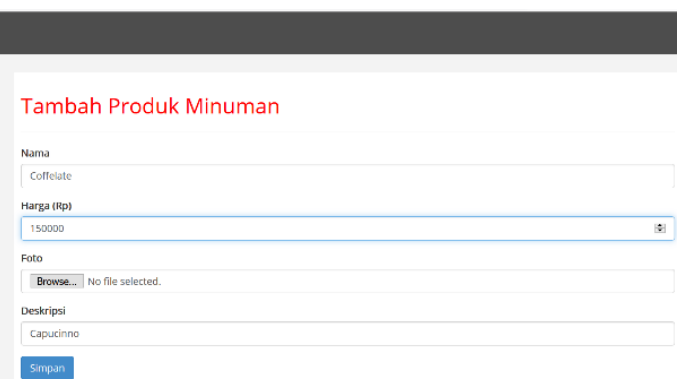

Gambar 7. Input Produk

Setelah input data produk, maka akan keluar data produk yang sudah di tambahkan, ataupun produk yang di update, seperti yang ditunjukkan pada gambar 8 .
Produk Minuman Cokla
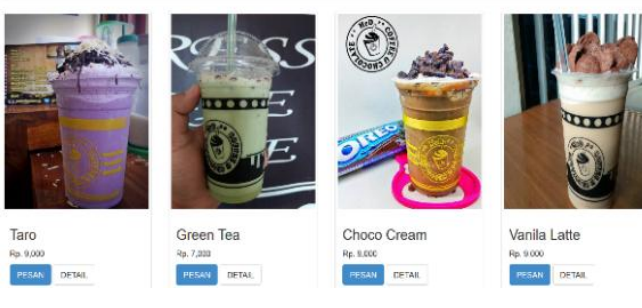

Green Tea

Choco Cream
Re 2 ece

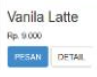

Gambar 8. Produk

Setelah melakukan input data produk, langkah selanjutnya adalah melihat data pemesanan yang sudah dilakukan oleh user/konsumen. Untuk melihat data pemesanan pada antar muka detail pemesanan seperti pada gambar 9.

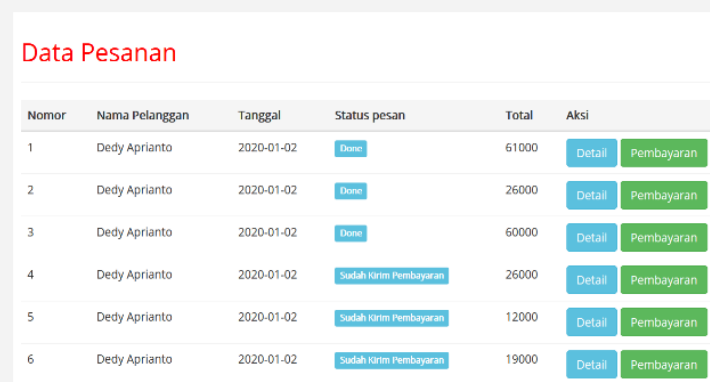

Gambar 9. Antar Muka Pemesanan

Antar muka selanjutnya adalah sistem back up data base, dimana sistem tersebut untuk melakukan proses database yang dilakukan dari aplikasi sistem informasi penjualan coklat di Mr.D. fungsi backup data base dengan menyimpan data input produk, data user, data pemesanan, data transaksi. Gambar 10 merupakan antar muka fungsi backup sistem.

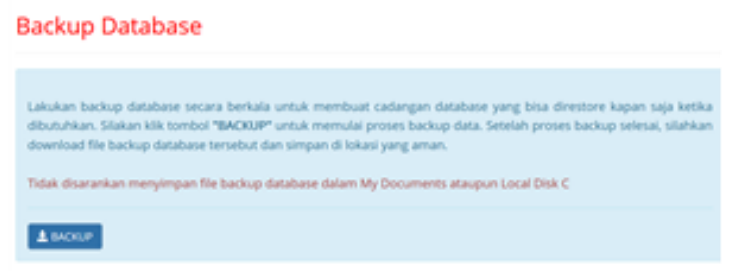

\section{Gambar 10. Antar Muka Backup DB}

\subsection{Pengujian Aplikasi}

Proses pada pengujian aplikasi dengan menggunakan metode black box yang dilakukan pada unit masukan maupun unit keluaran. Adapun tabel 1 dan tabel 2 merupakan contoh test case pengujian masukan dan hasil yang diharapkan. 


\begin{tabular}{|c|c|c|c|c|c|c|}
\hline \multicolumn{4}{|c|}{ Tabel 1. Uji Test Case Masukan } & \multicolumn{3}{|c|}{ Tabel 2. Test Case Keluaran } \\
\hline $\begin{array}{l}\text { Pengujian } \\
\text { Sistem }\end{array}$ & $\begin{array}{l}\text { Hasil yang } \\
\text { diharapkan }\end{array}$ & $\begin{array}{l}\text { Hasil } \\
\text { Uji }\end{array}$ & Kesimpulan & $\begin{array}{l}\text { Pengujian } \\
\text { Sistem }\end{array}$ & $\begin{array}{l}\text { Hasil yang } \\
\text { diharapkan }\end{array}$ & $\begin{array}{ll}\text { Hasil } & \text { Kesimpulan } \\
\text { Uji } & \end{array}$ \\
\hline $\begin{array}{l}\text { Insert Data } \\
\text { Produk }\end{array}$ & $\begin{array}{l}\text { Sistem } \\
\text { dapat } \\
\text { melakukan } \\
\text { proses }\end{array}$ & $\begin{array}{l}\text { Sistem } \\
\text { berjalan } \\
\text { dengan } \\
\text { baik }\end{array}$ & Sesuai & \multirow[t]{6}{*}{ Report } & $\begin{array}{l}\text { Sistem dapat } \\
\text { melakukan } \\
\text { cetak } \\
\text { produk }\end{array}$ & $\begin{array}{l}\text { Sistem } \\
\text { berjalan } \\
\text { dengan } \\
\text { baik }\end{array}$ \\
\hline $\begin{array}{l}\text { Edit Data } \\
\text { Produk }\end{array}$ & $\begin{array}{l}\text { Sistem } \\
\text { dapat } \\
\text { melakukan } \\
\text { proses }\end{array}$ & $\begin{array}{l}\text { Sistem } \\
\text { berjalan } \\
\text { dengan } \\
\text { baik }\end{array}$ & Sesuai & & $\begin{array}{l}\text { Sistem dapat } \\
\text { melakukan } \\
\text { cetak user }\end{array}$ & $\begin{array}{l}\text { Sistem } \\
\text { berjalan } \\
\text { dengan } \\
\text { baik }\end{array}$ \\
\hline $\begin{array}{l}\text { Update } \\
\text { Data } \\
\text { Produk }\end{array}$ & $\begin{array}{l}\text { Sistem } \\
\text { dapat } \\
\text { melakukan } \\
\text { proses }\end{array}$ & $\begin{array}{l}\text { Sistem } \\
\text { berjalan } \\
\text { dengan } \\
\text { baik }\end{array}$ & Sesuai & & $\begin{array}{l}\text { Sistem dapat } \\
\text { melakukan } \\
\text { cetak data } \\
\text { pemesanan }\end{array}$ & $\begin{array}{l}\text { Sistem } \\
\text { berjalan } \\
\text { dengan } \\
\text { baik }\end{array}$ \\
\hline $\begin{array}{l}\text { Delete } \\
\text { Data } \\
\text { Produk }\end{array}$ & $\begin{array}{l}\text { Sistem } \\
\text { dapat } \\
\text { melakukan } \\
\text { proses }\end{array}$ & $\begin{array}{l}\text { Sistem } \\
\text { berjalan } \\
\text { dengan } \\
\text { baik }\end{array}$ & Sesuai & & $\begin{array}{l}\text { Sistem dapat } \\
\text { melakukan } \\
\text { cetak data } \\
\text { transaksi }\end{array}$ & $\begin{array}{l}\text { Sistem } \\
\text { berjalan } \\
\text { dengan } \\
\text { baik }\end{array}$ \\
\hline $\begin{array}{l}\text { Insert data } \\
\text { User }\end{array}$ & $\begin{array}{l}\text { Sistem } \\
\text { dapat } \\
\text { melakukan } \\
\text { proses }\end{array}$ & $\begin{array}{l}\text { Sistem } \\
\text { berjalan } \\
\text { dengan } \\
\text { baik }\end{array}$ & Sesuai & & $\begin{array}{l}\text { Sistem dapat } \\
\text { melakukan } \\
\text { cetak data } \\
\text { ongkir }\end{array}$ & $\begin{array}{l}\text { Sistem } \\
\text { berjalan } \\
\text { dengan } \\
\text { baik }\end{array}$ \\
\hline $\begin{array}{l}\text { Delete data } \\
\text { User }\end{array}$ & $\begin{array}{l}\text { Sistem } \\
\text { dapat } \\
\text { melakukan } \\
\text { proses }\end{array}$ & $\begin{array}{l}\text { Sistem } \\
\text { berjalan } \\
\text { dengan } \\
\text { baik }\end{array}$ & Sesuai & & $\begin{array}{l}\text { Sistem dapat } \\
\text { melakukan } \\
\text { cetak data } \\
\text { pengiriman }\end{array}$ & $\begin{array}{l}\text { Sistem } \\
\text { berjalan } \\
\text { dengan } \\
\text { baik }\end{array}$ \\
\hline $\begin{array}{l}\text { Update } \\
\text { Data User }\end{array}$ & $\begin{array}{l}\text { Sistem } \\
\text { dapat } \\
\text { melakukan } \\
\text { proses }\end{array}$ & $\begin{array}{l}\text { Sistem } \\
\text { berjalan } \\
\text { dengan } \\
\text { baik }\end{array}$ & Sesuai & $\begin{array}{l}\text { Backup } \\
\text { Data Base }\end{array}$ & $\begin{array}{l}\text { Sistem dapat } \\
\text { melakukan } \\
\text { backup Data } \\
\text { base }\end{array}$ & $\begin{array}{l}\text { Sistem Sesuai } \\
\text { berjalan } \\
\text { dengan } \\
\text { baik }\end{array}$ \\
\hline $\begin{array}{l}\text { Insert Data } \\
\text { Pemesanan }\end{array}$ & $\begin{array}{l}\text { Sistem } \\
\text { dapat } \\
\text { melakukan } \\
\text { proses }\end{array}$ & $\begin{array}{l}\text { Sistem } \\
\text { berjalan } \\
\text { dengan } \\
\text { baik }\end{array}$ & Sesuai & \multirow{5}{*}{\multicolumn{3}{|c|}{$\begin{array}{l}\text { KESIMPULAN } \\
\text { Berdasarkan analisis, perencanaan, } \\
\text { implementasi, dan pembahasan yang telah } \\
\text { dilakukan dalam pembuatan Website } \\
\text { pemesanan minuman coklat di Mr.D ini dapat } \\
\text { diambil kesimpulan sebagai berikut: } \\
\text { 1. Rancangan Sistem Pemesanan minuman, } \\
\text { yang di usulkan penulis dapat mengatasi } \\
\text { kekurangan dari sistem yang berjalan di } \\
\text { Mr.D yaitu sebagai media promosi. } \\
\text { 2. Sistem Informasi Pemesanan Minuman di } \\
\text { Mr.D berbasis web memberikan kemudahan } \\
\text { bagi pelanggan untuk memesan makanan } \\
\text { tanpa harus datang ke tempat. Serta } \\
\text { mempermudah penjual dalam memproses } \\
\text { perhitungan pendapatan. }\end{array}$}} \\
\hline $\begin{array}{l}\text { Update } \\
\text { Data } \\
\text { Pemesanan }\end{array}$ & $\begin{array}{l}\text { Sistem } \\
\text { dapat } \\
\text { melakukan } \\
\text { proses }\end{array}$ & $\begin{array}{l}\text { Sistem } \\
\text { berjalan } \\
\text { dengan } \\
\text { baik }\end{array}$ & Sesuai & & & \\
\hline $\begin{array}{l}\text { Insert Data } \\
\text { Transaksi }\end{array}$ & $\begin{array}{l}\text { Sistem } \\
\text { dapat } \\
\text { melakukan } \\
\text { proses }\end{array}$ & $\begin{array}{l}\text { Sistem } \\
\text { berjalan } \\
\text { dengan } \\
\text { baik }\end{array}$ & Sesuai & & & \\
\hline $\begin{array}{l}\text { Update } \\
\text { data } \\
\text { Transaski }\end{array}$ & $\begin{array}{l}\text { Sistem } \\
\text { dapat } \\
\text { melakukan } \\
\text { proses }\end{array}$ & $\begin{array}{l}\text { Sistem } \\
\text { berjalan } \\
\text { dengan } \\
\text { baik }\end{array}$ & Sesuai & & & \\
\hline $\begin{array}{l}\text { Update } \\
\text { Data } \\
\text { Ongkir }\end{array}$ & $\begin{array}{l}\text { Sistem } \\
\text { dapat } \\
\text { melakukan } \\
\text { proses }\end{array}$ & $\begin{array}{l}\text { Sistem } \\
\text { berjalan } \\
\text { dengan } \\
\text { baik }\end{array}$ & Sesuai & & & \\
\hline
\end{tabular}




\section{DAFTAR PUSTAKA}

Andri, Kristanto. 2007. "Perancangan Sistem Informasi Dan Aplikasinya." Klaten: Gava Media.

Handita, Umar, Fadlillah. 2012. "Sistem Informasi Penjualan Berbasis Web Pada Usantex." Jurnal Emitor 12(1): 26-33

Hayat, A., \& Riyandho, U. (2019). RANCANG BANGUN SISTEM INFORMASI PENJUALAN BERBASIS WEB PADA PT SAMATOR GAS INDUSTRI. Journal of Innovation And Future Technology (IFTECH), 1(1), 112.

Moekijat. 2011. "Sistem Informasi Manajemen \& Definisi Data.” Bandung: Remaja Roskadarya.

Qomaruddin, Sudrajat, dan Supandi. 2018. "Sistem Informasi Penjualan Batik Berbasis Web Pada Toko 10S Pasar Grosir Setono." Jurnal Sinkron 2(2): 105-111

Roxana Bassi. 2010. "Practical Guide to Pilot Projects and Large Scale Deployment of ICTs in the Education Sector." GESCI: Global e-Schools and Communities Initiative 1.12: 1-48.

Sugiyono. 2018. Metode Penelitian Kuantitatif, Kualitatif Dan R\&D. Bandung: PT. Alfabet.

Yessy Fadhillah, dan Suprianto. 2017. "Sistem Informasi Penjualan Produk Krupuk Berbasis Web Responsive (Studi Kasus : Ud. Sumber Makmur).’Jurnal Sistem Informasi 8(1): 31-37 